Supporting information file

\title{
Reaction Kinetics Based Optimization of Furfural Production from Corncob Using a Fully Recyclable Solid Acid
}

\author{
Hairui Ji ${ }^{\text {a,c }}$, Liheng Chen ${ }^{\text {b,c }}$, J.Y. Zhu ${ }^{\text {c* }}$ Roland Gleisner $^{c}$, X. Zhang ${ }^{\text {a }}$ \\ ${ }^{a}$ National Energy R\&D Center for Biorefinery, Beijing Univ. Chem. Technol., Beijing, 100029, China \\ ${ }^{\mathrm{b}}$ South China Univ. Technol., Guangzhou, 510641, China \\ ${ }^{\mathrm{c}}$ USDA Forest Service, Forest Products Laboratory, Madison, WI, 53726, USA \\ * Corresponding author: jzhu@,fs.fed.us
}


Table S1. List of furfural production experiments conducted and results obtained.

\begin{tabular}{|c|c|c|c|c|c|c|c|c|c|c|}
\hline $\begin{array}{l}\text { Run } \\
\text { No }\end{array}$ & $\begin{array}{c}\text { P-TsOH } \\
(w t \%)\end{array}$ & $\begin{array}{c}\mathrm{T} \\
\left({ }^{\circ} \mathrm{C}\right)\end{array}$ & $\begin{array}{c}\mathrm{t} \\
(\min )\end{array}$ & $\mathrm{CHF}$ & $\begin{array}{l}\text { Distilled } \\
\text { furfural } \\
(\mathrm{g} / \mathrm{L})\end{array}$ & $\begin{array}{l}\text { Residual } \\
\text { furfural } \\
(\mathrm{g} / \mathrm{L})\end{array}$ & $\begin{array}{c}\text { Total } \\
\text { furfural } \\
\text { yield } \\
(\%)\end{array}$ & $\begin{array}{l}\text { WIS } \\
\text { yield } \\
(\%)\end{array}$ & $\begin{array}{c}\text { Glucan } \\
\text { remaining } \\
(\%)\end{array}$ & $\begin{array}{c}\text { Xylan } \\
\text { remaining } \\
(\%)\end{array}$ \\
\hline c9 & 5 & 60 & 30 & 0.07 & n.d. & 0.00 & 0 & 95.23 & 90.2 & 89.9 \\
\hline c10 & 10 & 60 & 30 & 0.14 & n.d. & 0.00 & 0 & 93.47 & 115.1 & 59.6 \\
\hline c11 & 15 & 60 & 30 & 0.21 & n.d. & 0.00 & 0 & 90.36 & 95.4 & 92 \\
\hline c14 & 10 & 60 & 70 & 0.32 & n.d. & 0.00 & 0 & 89.26 & 90.2 & 82.1 \\
\hline c15 & 15 & 60 & 70 & 0.48 & n.d. & 0.00 & 0 & 82.44 & 93.4 & 73.8 \\
\hline c16 & 20 & 60 & 70 & 0.64 & n.d. & 0.00 & 0 & 77.75 & 89.8 & 64.2 \\
\hline c5 & 5 & 80 & 30 & 0.69 & n.d. & 0.00 & 0 & 66.51 & 72.2 & 60.4 \\
\hline c17 & 10 & 80 & 30 & 1.38 & n.d. & 0.00 & 0 & 69.04 & 85 & 44 \\
\hline$c 21$ & 15 & 80 & 70 & 4.81 & n.d. & 0.00 & 0 & 60.88 & 95.2 & 35.8 \\
\hline c22 & 20 & 80 & 70 & 6.42 & n.d. & 0.51 & 3.91 & 59.56 & 86.8 & 30.2 \\
\hline c7 & 5 & 100 & 30 & 5.35 & n.d. & 0.00 & 0 & 62.22 & 89.2 & 31.3 \\
\hline c23 & 10 & 100 & 30 & 10.71 & n.d. & 0.52 & 3.98 & 58.45 & 89.9 & 25.5 \\
\hline c24 & 15 & 100 & 30 & 16.06 & n.d. & 0.57 & 4.38 & 57.15 & 84.5 & 23.6 \\
\hline c25 & 20 & 100 & 30 & 21.41 & n.d. & 1.26 & 9.64 & 54.53 & 74.4 & 19.3 \\
\hline c8 & 5 & 100 & 70 & 12.49 & n.d. & 0.05 & 0.37 & 60.02 & 89 & 26.2 \\
\hline c26 & 10 & 100 & 70 & 24.98 & n.d. & 1.10 & 8.39 & 54.88 & 79.5 & 18.3 \\
\hline$c 27$ & 15 & 100 & 70 & 37.47 & n.d. & 1.11 & 8.48 & 53.35 & 75.4 & 15.6 \\
\hline c28 & 20 & 100 & 70 & 49.97 & n.d. & 2.16 & 16.44 & 52.76 & 82.5 & 15.1 \\
\hline 71 & 5 & 120 & 30 & 33.83 & 1.06 & 0.29 & 4.65 & 55.19 & 90.5 & 14.9 \\
\hline 13 & 5 & 130 & 30 & 79.4 & 2.63 & 0.42 & 10.15 & 52.01 & 87.6 & 9.6 \\
\hline 17 & 10 & 130 & 30 & 158.8 & 5.34 & 1.21 & 22.21 & 49.24 & 89.2 & 3.7 \\
\hline 49 & 15 & 130 & 30 & 238.2 & 5.93 & 1.37 & 24.78 & 48.42 & 90.4 & 2.7 \\
\hline 33 & 20 & 130 & 30 & 317.6 & 14.51 & 1.96 & 54.39 & 48.22 & 90.6 & 1.4 \\
\hline 14 & 5 & 130 & 50 & 132.33 & 4.32 & 0.64 & 16.42 & 50.31 & 88.2 & 4.5 \\
\hline 18 & 10 & 130 & 50 & 264.66 & 8.72 & 1.58 & 34.46 & 48.9 & 86.2 & 1.8 \\
\hline 15 & 5 & 130 & 70 & 185.26 & 4.70 & 0.78 & 18.25 & 49.81 & 89.1 & 3.6 \\
\hline 19 & 10 & 130 & 70 & 370.53 & 7.22 & 1.27 & 28.38 & 48.46 & 87 & 1.6 \\
\hline 51 & 15 & 130 & 70 & 555.79 & 10.06 & 2.09 & 40.96 & 48.93 & 86.4 & 1.4 \\
\hline 35 & 20 & 130 & 70 & 741.06 & 18.28 & 2.85 & 70.21 & 49.62 & 80.5 & 1.4 \\
\hline 16 & 5 & 130 & 90 & 238.2 & 5.14 & 0.88 & 20.1 & 49.22 & 84.5 & 3 \\
\hline 20 & 10 & 130 & 90 & 476.39 & 8.04 & 1.51 & 32.01 & 49.42 & 86.8 & 1.4 \\
\hline 1 & 5 & 140 & 30 & 178.82 & 3.77 & 0.77 & 15.31 & 49.06 & 78.4 & 3.1 \\
\hline 21 & 10 & 140 & 30 & 357.63 & 8.30 & 1.66 & 33.53 & 47.9 & 87.3 & 1.2 \\
\hline 53 & 15 & 140 & 30 & 536.45 & 16.90 & 2.98 & 66.45 & 51 & 87.3 & 1.3 \\
\hline 37 & 20 & 140 & 30 & 715.26 & 18.15 & 3.28 & 71.71 & 48.14 & 80.1 & 1.3 \\
\hline 2 & 5 & 140 & 50 & 298.03 & 6.43 & 1.82 & 28.34 & 48.71 & 84.2 & 2.3 \\
\hline
\end{tabular}




\begin{tabular}{ccccccccccc}
3 & 5 & 140 & 70 & 417.24 & 6.42 & 1.34 & 26.18 & 49.27 & 85.8 & 2.4 \\
23 & 10 & 140 & 70 & 834.47 & 14.17 & 2.64 & 56.36 & 48.65 & 80.4 & 1.2 \\
55 & 15 & 140 & 70 & 1251.71 & 12.91 & 2.84 & 53.29 & 48.78 & 69.3 & 0 \\
39 & 20 & 140 & 70 & 1668.95 & 14.98 & 3.18 & 61.34 & 47.93 & 56 & 0 \\
4 & 5 & 140 & 90 & 536.45 & 10.45 & 2.29 & 43.1 & 48.8 & 87.1 & 1.3 \\
5 & 5 & 150 & 30 & 387.55 & 9.49 & 1.74 & 37.6 & 47.37 & 82.8 & 1.2 \\
25 & 10 & 150 & 30 & 775.11 & 19.00 & 3.85 & 76.93 & 46.14 & 71.7 & 0 \\
57 & 15 & 150 & 30 & 1162.66 & 17.77 & 2.90 & 68.81 & 45.42 & 67.7 & 0 \\
41 & 20 & 150 & 30 & 1550.21 & 16.37 & 3.81 & 68.53 & 43.78 & 53.6 & 0 \\
6 & 5 & 150 & 50 & 645.92 & 13.62 & 2.28 & 53.01 & 47.25 & 79.4 & 1.3 \\
7 & 5 & 150 & 70 & 904.29 & 9.07 & 1.94 & 37.18 & 47.58 & 81.8 & 1.3 \\
27 & 10 & 150 & 70 & 1808.58 & 13.73 & 2.81 & 55.73 & 46.03 & 51.2 & 0 \\
59 & 15 & 150 & 70 & 2712.87 & 11.45 & 2.08 & 45.3 & 43.83 & 27.8 & 0 \\
43 & 20 & 150 & 70 & 3617.16 & 6.20 & 1.67 & 26.96 & 41.97 & 20.8 & 0 \\
8 & 5 & 150 & 90 & 1162.66 & 14.02 & 2.63 & 55.83 & 46.72 & 78.1 & 1.4 \\
9 & 5 & 160 & 30 & 810.48 & 13.93 & 2.94 & 56.93 & 47.05 & 75 & 1.1 \\
29 & 10 & 160 & 30 & 1620.97 & 17.01 & 3.85 & 70.68 & 43.54 & 56.5 & 0 \\
61 & 15 & 160 & 30 & 2431.45 & 12.08 & 2.58 & 49.5 & 39.94 & 34.3 & 0 \\
45 & 20 & 160 & 30 & 3241.93 & 11.17 & 1.90 & 43.62 & 39.13 & 16.1 & 0 \\
10 & 5 & 160 & 50 & 1350.8 & 16.95 & 3.49 & 68.9 & 45.14 & 65.1 & 1 \\
11 & 5 & 160 & 70 & 1891.13 & 18.76 & 3.58 & 74.99 & 43.02 & 50.1 & 0 \\
31 & 10 & 160 & 70 & 3782.25 & 7.11 & 1.76 & 30.2 & 40.61 & 18.7 & 0 \\
f1 & 5 & 165 & 43 & 1658.87 & 13.43 & 3.16 & 56.36 & 48.65 & 80.4 & 1.2 \\
f2 & 10 & 160 & 30 & 1620.97 & 16.94 & 3.79 & 70.21 & 49.62 & 80.5 & 1.4 \\
f3 & 15 & 156 & 27 & 1635.82 & 13.05 & 3.29 & 55.73 & 46.03 & 51.2 & 0.0 \\
f4 & 20 & 153 & 24 & 1553.05 & 17.59 & 3.67 & 71.71 & 48.14 & 80.1 & 1.3 \\
\hline
\end{tabular}

n.d. stands for no distillation at low temperature. 